\title{
The Study on First-Aid Education of Disaster for Primary School Student in China
}

\author{
Min Zhang, Li Li Guo, Min Xu* \\ Beihua University, Jilin, China \\ Email: zhangminjl@163.com
}

Received April 2013

\begin{abstract}
Objective: To investigate current status of school disaster education of primary school students and analyze potential causes and discuss how to establish a corresponding education mode. Methods: The questionnaires of disaster knowledge for Primary and middle school students were used in this study and a random sampling method was adopted for the research. Results: The primary school students maintained the high rate of disaster attention. 73\% primary school students had pay attention to the occurrence of disasters; more than $75 \%$ primary school students were lack of knowledge on disaster prevention and mitigation and $58.5 \%$ students were not satisfied with school disaster education work. Conclusions: There was dislocation between the way and mode of school disaster education. It might improve the quality of the disaster education and expand the disaster education to promote the development of disaster education.
\end{abstract}

Keywords: School Disaster Education; Primary School Students

\section{Introduction}

The school accidents are frequently major accidents. The campus security has become the focus in the whole society. Many scholars regard the accident injury of students as the most severe problem in public health [1-3]. In China, more than 40 children are died of fire and traffic accident per day on average. Safety education is the foundation of disaster prevention. In the United States, Japan and many other countries, the education of emergency and disaster mitigation has been a kind of basic quality education $[4,5]$. But in China, the disaster emergency education is still in the initial stage and the training of aid skills is still weak. Therefore, to explore the research situation of disaster emergency teaching education in the youth of our country could provide a theoretical basis for the system of the teenage year disaster emergency teaching.

\section{Methods}

\subsection{Subjects}

600 primary school students (from Grade 3 to Grade 6) were randomly selected from Changchun primary school to complete questionnaires. 564 students completed the questionnaire thoroughly. 36 primary school students were not able to complete the questionnaire. The response rate of effective questionnaires was $94 \%$ (564/600).

\footnotetext{
"Corresponding author.
}

\subsection{Instruments}

The questionnaires of disaster knowledge for Primary and middle school students' focus on the students' understanding of disaster, the degree of disaster affected students, the students' ability of dealing with disaster, the recognition degree of disaster education, the depth of investigation, the response ability of disaster, the knowledge and education level of disaster.

\subsection{Data Analysis}

All data were analyzed with the SPSS 13.0 statistical analysis software package [3].

\section{Results}

\subsection{The High Rate of Disaster Attention in the School Student}

The primary school students maintain the high rate of disaster attention, $73 \%$ of primary school students have paid attention to the occurrence of disasters and have understood related disaster knowledge. Around 57.2\% of primary school students were more care about all kinds of potential safety problems.

\subsection{The Function of Disaster Education in First-Aid}

Only $3.85 \%$ of primary school students had the negative 
opinion on that disaster education could reduce the damage of primary school students, and more than $75 \%$ of primary school students were lack of knowledge on disaster prevention and mitigation, and need to keep learning. At the same time, $91.5 \%$ of students consider that disaster education beneficial to disaster self-help.

\subsection{The Ways of Study Disaster Education}

In this study, $91 \%$ of students had three or more ways to study the relevant knowledge of disaster education, Internet $(60.1 \%)$ is the main way and television (29.3\%), newspapers, school education etc.

\subsection{The Satisfaction Survey of School Disaster Education}

In the survey, only $9.4 \%$ of students attended the school related training or courses; $58.5 \%$ of students were not satisfied with school disaster education work (Table 1), $45 \%$ of students think that the degree of school disaster education work is not enough, at the same time, $43.5 \%$ of students think the education mode is formalized, which are the main problems existed in the school disaster education.

\section{Discussion}

In this study, our result showed that the current situation of the disaster education was not optimistic. $73 \%$ of students had paid attention to the occurrence of disasters, but only $9.5 \%$ of students had participated in the school organization of disaster education activities, therefore,

Table 1. The satisfaction survey of school disaster education.

\begin{tabular}{lc}
\hline Are you take part in the school disaster education? & $\mathrm{n}(\%)$ \\
\hline yes & $53(9.4 \%)$ \\
no & $511(90.6)^{*}$
\end{tabular}

The Satisfaction survey of school disaster education

\begin{tabular}{lc} 
Great & $56(10 \%)$ \\
Good & $58(10.2 \%)$ \\
Average & $120(21.3 \%)$ \\
Not & $330(58.5 \%)^{* * *}$ \\
\hline
\end{tabular}

*denotes a significant difference compared to the other group $(\mathrm{P}<0.05)$; ${ }^{* *}$ denotes a significant difference compared to the other group $(\mathrm{P}<0.05)$. students had fully understood disasters events but did not prevent and reduce the damage of disasters. Students tended to focus on disaster that had happened, but very few students knew how to deal with the occurrence of disaster. This phenomenon reflected poor practice ability of the students. Therefore, there were serious dislocations in practice.

$60.1 \%$ of students usually studied the relevant knowledge of disasters by digital media $(84.14 \%$ of the students hoped to study the relevant knowledge of disasters through elective courses and practical exercises in disasters). Therefore, the contents of school disaster education were not comprehensive exhibition of disaster knowledge, at the same time, the school disaster education was mainly completed through releasing disaster prevention manual and lectures. There were the dislocation between the way and mode of school disaster education which caused students to lose faith. It is the main reason.

In the present condition, the immature disaster education was largely due to not getting enough reconstruction. It might improve the quality of the disaster education and expand the disaster education to promote the development of disaster education.

\section{Acknowledgements}

This work was partially supported by the governmental education department of Jilin province under grant (201180).

\section{REFERENCES}

[1] P. La, T. Richard, et al., "Resource for Crisi Management in School."

[2] Emergency Response and Crisis Management (ERCM) Technical Assistance, ERCM Expree, Volume 2, Lssue 8, US Department of Education.

[3] Fuentes, E. Garza and M. Raymond, "Being Prepare: The School Emergency Response Plan Handbook.”

[4] C. Watanabe, J. Okumum, T. Y. Chiu, et al., "Social Support and Depressive Symptoms among Displaced Older Adults Following the 1999 Taiwan Earthquake,” Journal of Traumatic Stress, Vol. 17, No. 1, 2004, pp. 63-67. http://dx.doi.org/10.1023/B:JOTS.0000014678.79875.30

[5] J. F. Phifer, "Psychological Distress and Somatic Symptoms after Natural Disaster: Differential Vulnerability among Older Adults," Psychology and Aging, Vol. 5, No. 3, 1990, pp. 412-420.

http://dx.doi.org/10.1037/0882-7974.5.3.412 